\title{
Análise de Estresse Vegetativo, Associado às Variáveis Climáticas no Nordeste do Brasil e nos Municípios do Ceará (Fortaleza, Jaguaruana e Campos Sales)
}

\author{
Aldenia Ribeiro dos Santos Gomes ${ }^{1}$, Vasco Barreto Braga ${ }^{1}$, Jose Maria Brabo Alves ${ }^{2}$ (D), \\ Emerson Mariano da Silva ${ }^{2}$ (D), Camila Ribeiro dos Santos Gomes ${ }^{3}$, \\ Micaelle Ribeiro dos Santos Gomes ${ }^{3}$ \\ ${ }^{1}$ Curso de Mestrado Profissional em Climatologia e Aplicações em Países da CPLP e África, \\ Universidade Estadual do Ceará, Fortaleza, CE, Brasil. \\ ${ }^{2}$ Departamento de Pós-Graduação em Climatologia e Aplicações em Países da CPLP e África, \\ Universidade Estadual do Ceará, Fortaleza, CE, Brasil. \\ ${ }^{3}$ Departamento de Pós-Graduação em Bioquímica Universidade Federal do Ceará, Fortaleza, \\ CE, Brasil.
}

Recebido em: 28 de Março de 2020 - Aceito em: 30 de Junho de 2020

\begin{abstract}
Resumo
A região do Nordeste do Brasil - NEB possui $1.561 .177,8 \mathrm{~km}^{2}$, destes aproximadamente $61,7 \%$ constitui o Semiárido brasileiro, formando um território especial com médias anuais de temperaturas entre $23{ }^{\circ} \mathrm{C}$ e $27{ }^{\circ} \mathrm{C}$, de precipitações inferiores a $800 \mathrm{~mm}$ e umidade relativa em torno de $50 \%$ e altas taxas de evaporação da ordem de $2.000 \mathrm{~mm}^{\mathrm{ano}} \mathrm{o}^{-1}$, o que torna o NEB bastante afetado pela variabilidade da maioria das variáveis climáticas. A precipitação e a temperatura do ar na superfície constituem variáveis meteorológicas vitais no ciclo hidrológico, além de suas influências nas atividades humanas, possuem forte influência na manutenção da cobertura vegetal e consequentemente no ecossistema natural de uma região. Esse estudo investigou a correlação existente entre as variáveis climáticas e variáveis relacionadas à precipitação e temperatura do ar na superfície, com a cobertura vegetal da região utilizando o índice de Vegetação de Diferença Normalizada - NDVI, índice de condição da vegetação - VCI e o índice de Condição de Temperatura - TCI. Foi investigado como esses índices $V C I, T C I$ e $N D V I$ respondem a temperatura do ar medida em alguns municípios do estado do Ceará: Fortaleza - região de elevado desenvolvimento urbano; Jaguaruana - característica rural e Campos Sales - Sertão Central. Foram utilizados dados de sensoriamento remoto (NOAA-NESDIS) em uma série histórica (1982 a 2015) e classificado em: períodos sazonais, períodos decenais e anos de contrastes climáticos (La Niña, El Niño e Condições Normais). Os dados foram trabalhados em rotinas FORTRAN e GrADS (Grid Analysisand Display System). Os resultados obtidos mostraram correlação positiva entre os índices analisados (NDVI, VCI e TCI) na região semiárida do NEB. Quando analisadas outras áreas da região NEB com maiores índices de precipitações, os resultados não foram tão perceptíveis. $O$ monitoramento do estresse térmico sazonal e interanual nas sub-regiões semiáridas do NEB, leste do NEB e sul do NEB foi bastante significativo e favoreceu as regiões com baixos índices de precipitações indicando que o $V C I, T C I$ e $N D V I$ podem ser utilizados para monitoramento de secas, porém esses índices podem obter diferentes resultados e ruídos quando avaliados separadamente ou em regiões com altas taxas de precipitação. O coeficiente de correlação de Pearson foi usado para correlacionar a temperatura do "Ar" da superfície medida nas estações dos municípios de Fortaleza, Jaguaruana e Campos Sales com os índices de TCI e VCI médios e demonstrou uma Forte Correlação $(0,80)$. A partir do teste $t$-Student foi extraído o coeficiente crítico de correlação $(r c)$, que demonstrou grande significância 95\% com os dados observados, comprovando que o TCI e VCI podem ser indicativos de condição de estresse na vegetação desses municípios, pois possui uma forte correlação com as variáveis meteológicas analisadas.
\end{abstract}

Palavras-chave: estresse vegetativo, variabilidade climática, sensoriamento remoto.

Autor de correspondência: Aldenia Ribeiro dos Santos Gomes, aldeniarsg@gmail.com. 


\title{
Vegetative Stress Analysis, Associated with Climate Variables in Northeast Brazil and in the Municipalities of Ceará (Fortaleza, Jaguaruana and Campos Sales)
}

\begin{abstract}
The Northeast region of Brazil - NEB has $1,561,177.8 \mathrm{~km}^{2}$, of which approximately $61.7 \%$ constitutes the Brazilian semiarid, forming a special territory with annual temperature averages between $23{ }^{\circ} \mathrm{C}$ and $27{ }^{\circ} \mathrm{C}$, with rainfall below $800 \mathrm{~mm}$ and relative humidity around $50 \%$ and high evaporation rates in the order of 2,000 mm year ${ }^{-1}$, which makes NEB very affected by the variability of most climatic variables. The loss and temperature of the air on the surface extinguished vital meteorological conditions in the hydrological cycle, in addition to its influences on human activities, has a strong influence on the maintenance of vegetation cover and consequently on the natural ecosystem of a region. This study investigated the existing correlation between climatic variables and variables related to the exclusion and temperature of the surface air, with the vegetation cover of the region using the Normalized Difference Vegetation index - NDVI, vegetation condition index - VCI and the Temperature Condition Index - TCI. It was investigated how these $V C I, T C I$ and NDVI indices measured the air temperature in some municipalities in the state of Ceará: Fortaleza - region of high urban development; Jaguaruana - rural characteristic and Campos Sales - Sertão Central. Remote sensing data (NOAA-NESDIS) was used in a historical series (1982 to 2015) and classified into: seasonal periods, ten-year periods and years of climatic contrasts (La Niña, El Niño and Normal Conditions). The data were processed in FORTRAN and GrADS (Grid Analysisand Display System) routines. The results of the positive trend between the positive indices (NDVI, VCI and TCI) in the semi-arid region of NEB. When analyzing other areas of the NEB region with higher precipitation rates, the results were not as noticeable. The monitoring of seasonal and interannual thermal stress in the semi-arid sub-regions of the NEB, east of the NEB and south of the NEB was quite significant and favored the regions with low levels of precipitation indicating that the $V C I, T C I$ and $N D V I$ can be used for monitoring droughts, however, these indices can obtain different results and noise when supplied or in regions with high graduation rates. Pearson's correlation coefficient was used to correlate the "Air" temperature of the surface measured at stations in the cities of Fortaleza, Jaguaruana and Campos Vendas with the mean TCI and VCI indexes and that Strong Correlation (0.80). From the t-Student test the critical correlation coefficient (rc) was extracted, which has a $95 \%$ significance with the observed data, proving that the $T C I$ and $V C I$ can be indicative of stress conditions in the cities vegetation, as it has a strong correlation with the meteorological variables analyzed.
\end{abstract}

Keywords: vegetative stress, climaticvariability, remote sensing.

\section{Introdução}

A região NEB faz limite com o Oceano Atlântico ao norte e a leste; ao oeste se limita com os Estados do Pará, Tocantins e Goiás e ao sul com os Estados de Minas Gerais e Espírito Santo, conforme Silva et al. (2006). Na região predominam quatro tipos de clima: Tropical Semiárido (encontrado em parte do Piaú, parte da Zona do Ser tão, no Ceará, Rio Grande do Norte, Paraíba, Pernambuco, Sergipe e Bahia); Tropical (Predominante em grande parte do Maranhão, do Piauí, do Ceará e da Bahia); Tropical Úmido ou Tropical Litorâneo (Litoral e estende-se do Rio Grande do Norte até o sul da Bahia.) e Equatorial Úmido (Faixa estreita do Maranhão, fronteira com o estado do Pará), (Rocha et al., 2010).

A vegetação da região semiárida é caracterizada pela caatinga arbustiva que perde a folhagem durante a estiagem e floresce quando chove, restingas, mangues, vegetação rupestre, mata Atlântica, vegetação de praias, dunas e ribeirinhas. Compondo dessa forma os seguintes domínios fitoclimáticos: o agreste, a zona da mata, a zona amazônica e os campos cerrados (IBGE, 1985).
No geral as variáveis meteorológicas como umidade relativa, direção e velocidade de vento e variações de temperatura estão associadas de forma direta ou indireta a ocorrência de precipitação Santos et al. (2009) e Santos (2006). A região semiárida no interior do NEB possui precipitação inferior a $500 \mathrm{~mm} / \mathrm{ano}$. Enquanto na região Leste possui precipitação anual acima de $1500 \mathrm{~mm}$ (Kousky e $\mathrm{Chu}, 1978)$. No setor norte da região possui chuvas anuais entre 1000 e $1200 \mathrm{~mm}$ (Hastenrath e Heller, 1977). Segundo Uvo e Berndtsson (1996) o regime de chuva no Nordeste é influenciado por vários mecanismos tais como o fenômeno El Niño e La Niña, que constituem as forçantes dominantes de anomalias de precipitação no NEB Andreoli e Kayano (2007), Temperatura da superfície do mar - TSM, os Ventos Alísios, a Zona de Convergência Intertropical - ZCIT (uma banda de nuvens formada pela confluência entre os ventos alísios norte e sul, em baixos níveis no oceano Atlântico) e os Vórtices Ciclônicos de Altos Níveis - VCAN (constituído por um conjunto de nuvens causadoras de chuva que possui forma de um círculo girando no sentido horário, com trajetória de leste para oeste) segundo estudos (Gan, 1982). 
O El Niño é um fenômeno que ocorre devido ao aquecimento nas águas no Oceano Pacífico produzindo massas de ar quentes e úmidas, resultando em aumento de chuvas em algumas áreas do planeta e secas severas em outras áreas. Esse fenômeno reduz as chuvas no Nordeste do Brasil, Amazônia oriental, Indonésia e Austrália, e aumento de chuvas no sul do Brasil, no Centro-Oeste e boa parte do Sudeste do Brasil. O Fenômeno La Niña, ao contrário do El Niño, é caracterizado pelo esfriamento nas águas do oceano Pacífico, sendo um dos fatores de sua existência causada pelo aumento dos ventos alísios sobre a superfície do Pacífico Tropical. Uma das consequências da presença do fenômeno La Niña é causar mais precipitação na Amazônia, no Nordeste, partes do Sudeste e baixas temperaturas em parte da Europa e na América do Norte segundo Chiang et al. (2000). Na Tabela 1 são apresentados os anos de incidência de eventos de El Niño e La Niña em uma série histórica.

No Nordeste existem diferentes regimes de chuvas. Na parte norte do NEB a estação chuvosa ocorre entre os meses de março a maio, devido ao deslocamento da ZCIT para latitudes ao sul no Hemisfério Norte, afetando as precipitações nos meses de abril e maio. Segundo Cavalcanti (1982) a ZCIT provoca baixas pressões na região NEB, contribuindo para a formação de nuvens do tipo cumulonimbus, que são nuvens convectivas com desenvolvimento vertical que podem alcançar a estratosfera e produzir bastante chuva, neve, granizo e raios, na costa conforme Echer et al., (2006). O estado do Ceará, que faz parte do norte do NEB, possui sua maior concentração de chuva no período conhecido como quadra chuvosa entre os meses de fevereiro a maio (Alves et al., 1998).

$\mathrm{Na}$ parte sul e sudeste do NEB a estação chuvosa ocorre durante nos meses de dezembro a fevereiro, devido às frentes frias vindas do sul nos meses de novembro a fevereiro. $\mathrm{Na}$ costa leste da região nordeste as chuvas ocorrem entre maio a julho segundo Kousky (1979), essas chuvas sofrem influência das atividades de circulação de brisa, Ondas de Leste, e a ação das frentes frias que se propagam ao longo da costa (Rao et al., 1993).

O estudo de Servain e Lukas (1990) sobre os ventos do Atlântico Sul, demonstraram que esse fenômeno favorece a ocorrência chuva devido às zonas de convergência noturna associados à brisa terrestre. As chuvas na região Nordeste também sofrem influência de VCAN conforme Gan (1982), eles ocorrem entre os meses de setembro a abril, tendo maior incidência no mês de janeiro e favorecem as precipitações ocorridas principalmente em áreas ao norte e nordeste da região NEB.

Segundo o relatório do Painel Intergovernamental sobre Mudanças Climáticas - IPCC, estabelecido pelas Nações Unidas e pela Organização Meteorológica Mundial (2007) projeta-se que até final do século XXI, a vegetação semiárida do Nordeste tenderá a ser substituída por vegetação de terras áridas, em áreas mais secas haverá aumento da salinização hídrica, desertificação de terras agrícolas e diminuição nos padrões de precipitação. Devido à região nordeste ser mais vulnerável no Brasil às mudanças climáticas conforme o PBMC - Painel Brasileiro de Mudanças Climáticas (2013), esta região conhecida como semiárido, ou somente "sertão" terá, segundo modelos globais do IPCC AR4, reduções de chuva assim como um aumento da temperatura que pode chegar de $3{ }^{\circ} \mathrm{C}$ a $4{ }^{\circ} \mathrm{C}$ ainda na segunda metade do século XXI devido principalmente, às emissões de gases de efeito estufa.

A deficiência de precipitação em determinada área ou região por um período prolongado de tempo resultando em falta de água para consumo humano, animal e ou agrícola e atividades industriais e ambientais é definida como "Seca" (NDMC, 2007). Alguns autores como Kogan (1995); Kogan e Sullivan (1993), utilizaram dados de monitoramento de satélite para determinar a cobertura

Tabela 1 - Incidência Temporal de fenômeno El Niño e La Niña em uma série histórica de 66 anos.

\begin{tabular}{|c|c|c|c|c|c|c|}
\hline \multicolumn{4}{|c|}{ El Niño } & \multicolumn{3}{|c|}{ La Niña } \\
\hline Fraco & Moderado & Forte & Muito forte & Fraco & Moderado & Forte \\
\hline $1952-53$ & $1951-52$ & $1957-58$ & $1982-83$ & $1954-55$ & $1955-56$ & $1973-74$ \\
\hline $1953-54$ & $1963-64$ & $1965-66$ & $1997-98$ & $1964-65$ & $1970-71$ & $1975-76$ \\
\hline $1958-59$ & $1968-69$ & $1972-73$ & $2015-16$ & $1971-72$ & $1995-96$ & $1988-89$ \\
\hline $1969-70$ & $1986-87$ & $1987-88$ & & $1974-75$ & $2011-12$ & 1998-99 \\
\hline $1976-77$ & $1994-95$ & $1991-92$ & & $1983-84$ & & $1999-00$ \\
\hline $1977-78$ & $2002-03$ & & & $1984-85$ & & 2007-08 \\
\hline $1979-80$ & $2009-10$ & & & 2000-01 & & 2010-11 \\
\hline $2004-05$ & & & & $2005-06$ & & \\
\hline 2006-07 & & & & 2008-09 & & \\
\hline \multirow[t]{2}{*}{ 2014-15 } & & & & 2016-17 & & \\
\hline & & & & $2017-18$ & & \\
\hline
\end{tabular}

Fonte: http://ggweather.com/enso/oni.htm disponível em 15 abr.2018. 
vegetal e condição de estresse da vegetação e seca de uma determinada região. O Índice de Vegetação de Diferença Normalizada - NDVI, é obtido a partir de um sensor a bordo do satélite meteorológico, com grande resolução para aplicações em meteorologia (AVHRR-3/NOAA Radiômetro avançado de alta resolução/Administração Atmosférica Oceânica Nacional). O NDVI é calculado pela razão ou diferença dos valores de refletância da faixa infravermelho próximo $(0,725$ à $1,10 \mu \mathrm{m})$ e da faixa visível $(0,4$ à $0,7 \mu \mathrm{m})$ e varia de +1 a -1 (Perez, 2003).

$$
N D V I=\frac{(I R-V I S)}{(I R+V I S)}
$$

Segundo Kogan (1995) Um índice de vegetação ideal deve ser sensível à vegetação, insensível a influência do solo e não ter interferências atmosféricas. $\mathrm{O} N D V I$ utiliza bandas espectrais sensiveis à absorção da clorofila nas plantas. Portanto quando a vegetação está em desenvolvimento, o $N D V I$ tendem a valores positivos. O VCI - Indice de Condição de Vegetação é derivado do Índice de $N D V I$ e corresponde à diferença entre a radiação no infravermelho próximo medido pelo AVHRR e a reflectância no canal visível.

$$
V C I=100 \times \frac{\left(N D V I-N D V I_{\min }\right)}{\left(N D V I_{\max }-N D V I_{\min }\right)}
$$

O $N D V I_{\max }$, e $N D V I_{\min }$ são composições de $N D V I$ obtidas pelo período de 10 dias. O TCI - Indice de Condição de Temperatura é derivado das radiações medidas com o AVHRR (varia de 10,3 a 11,3 $\mu \mathrm{m}$ ), que são convertidas em BT - temperatura de brilho.

$$
T C I=100 \times \frac{\left(T_{\max }-T\right)}{\left(T_{\max }-T_{\min }\right)}
$$

Kogan (1997) também utilizou o VCI e o TCI para determinar o estresse da vegetação relacionada à precipitação e à temperatura que ocorre durante uma seca ou estiagem.

Este estudo buscou investigar o estresse vegetativo correlacionado às variáveis climáticas predominantes na região nordeste, para isso foi utilizado dados de satélite: TCI, VCI; NDVI e dados In situ de temperatura do ar superfície, umidade relativa do ar e precipitação. Foi avaliado também o quanto os índices de variação e de estresse de umidade, medido por satélite, se relacionam com medidas de temperatura do ar a superfície mensal observada em áreas do Ceará: Fortaleza, Jaguaruana e Campos Sales.

\section{Materiais e Métodos}

Os dados mensais de temperatura, pressão e precipitação da região NEB e dos demais municípios do Estado do Ceará (Fortaleza, Campos Sales e Jaguaruana) no período de 1982-2015, foram obtidas do Instituto Nacional de
Meteorologia - INMET e Fundação Cearense de Meteorologia - FUNCEME. Os índices de vegetação: $N D V I, V C I$ e $T C I$ foram obtidos do banco de dados de Sensoriamento Remoto AVHRR, NOAA-NESDIS período de 1982-2015. Estes dados estão em pontos de grade $0,144^{\circ}$ de latitude e longitude (Kogan e Sullivan, 1993).

A metodologia abordada seguiu os seguintes passos:

- Cálculo de variabilidade sazonal interanual de $N D V I$ (estações do ano: Verão, Outono, Inverno, Primavera) sobre o Nordeste Região Semiárida $\left(2^{\circ} \mathrm{S}-12^{\circ} \mathrm{S}\right.$ e $\left.45^{\circ} \mathrm{W}-37^{\circ} \mathrm{W}\right)$, Sul do Nordeste $\left(15^{\circ} \mathrm{S}-20^{\circ} \mathrm{S}\right.$ e $50^{\circ} \mathrm{W}-$ $\left.34^{\circ} \mathrm{W}\right)$ e Leste do Nordeste $\left(2^{\circ} \mathrm{S}-15^{\circ} \mathrm{S}\right.$ e $37^{\circ} \mathrm{W}-$ $\left.34^{\circ} \mathrm{W}\right)$ do Brasil do banco de dados da NOAA-NESDIS;

- Cálculo da variabilidade espacial do percentual médio de estresse térmico de $T C I$ e $V C I$, nas três décadas: 1982 a 1991; 1992 a 2001 e 2002 a 2011, sobre o Nordeste do Brasil, banco de dados da NOAA-NESDIS;

- Cálculo de variabilidade média interanual de $V C I$ e $T C I$ (janeiro a dezembro) associada a condições de estresse sobre o Nordeste do Brasil, banco de dados da NOAANESDIS para o período de 1982-2011;

- Cálculo de médias interanuais de precipitação dos municípios de Fortaleza, Campos Sales, e Jaguaruana na série histórica de 1979 a 2015;

- Avaliação das anomalias sazonais para alguns anos de contrastes, para os períodos de La Niña, El Niño e Condições Normais, das variáveis de $N D V I, V C I$, e $T C I$ do banco de dados da NOAA-NESDIS;

- Foram escolhidos três municípios do estado do Ceará para esta pesquisa baseado em suas características e pontos extremos: Fortaleza - com alto índice de desenvolvimento urbano, e municípios com característica interiorana e rural; Jaguaruana (Sertão Central) e Campos Sales (Setor sul do Estado);

- Foi avaliada a correlação linear mensal entre a temperatura do ar de superfície medida nas estações dos municípios de Fortaleza, Campos Sales e Jaguaruana no Ceará e os índices médios de TCI e VCI dessas coordenadas geográficas. Algumas métricas foram usadas nos cálculos citados acima e outras serviram para inferir as comparações entre os dados usados no estudo: O coeficiente de correlação de Pearson $(r)$; Teste $t$-Student e o coeficiente crítico de correlação $\left(r_{c}\right)$ conforme Tabela 2.

$\mathrm{O}$ coeficiente de correlação de Pearson $(r)$ fórmula 4 (Tabela 2) descreve o grau de colinearidade entre os dados simulados e observados, Os valores de $X$ e $Y$ nas fórmulas representam as variáveis a serem comparadas. O coeficiente de correlação de Pearson foi utilizado para indicar a concordância entre diferentes conjuntos de dados. Sendo que ele representa o desvio padrão da variável simulada e representa o desvio padrão da variável observada.

$\mathrm{O}$ teste $t$-Student, por exemplo, pode inferir o nível de significância nas correlações entre os campos de eventos simulados com os das reanálises (Huang e Paes, 2009; 
Tabela 2 - Índices estatísticos com seus respectivos símbolos e fórmulas.

\begin{tabular}{lccc} 
Índice & Símbolo & Fórmula & Equação \\
\hline Coeficiente de correlação de Pear- & $r$ & $r=\frac{1}{n} \sum_{i=1}^{n} \frac{X_{i} Y_{i}}{\sigma_{X} \sigma_{y}}$
\end{tabular}

Fonte: Devore (2006).

Menezes et al., 2008). O teste usado é dado pela expressão matemática na fórmula 5 (Tabela 2) em que, $N$ é o número de pares de dados. A partir da expressão da fórmula 5 é extraído o coeficiente crítico de correlação $\left(r_{c}\right)$, fórmula 6 (Tabela 2). Ele é usado para aceitar ou rejeitar o teste de hipótese. Dessa forma quando o valor de " $r$ " em módulo for maior que o do " $r_{c}$ " a correlação é considerada significativa.

Os valores de $r$ geralmente na vizinhança tanto de -1 quanto de +1 indicam uma relação relativamente forte, e valores de $r$ na vizinhança de 0 (zero) indicam uma relação fraca ou quase inexistente (Witte e Witte, 2005).

- A Tabela 3 apresenta uma análise qualitativa e quantitativa do coeficiente de correlação de Pearson e as classificações da sua magnitude.
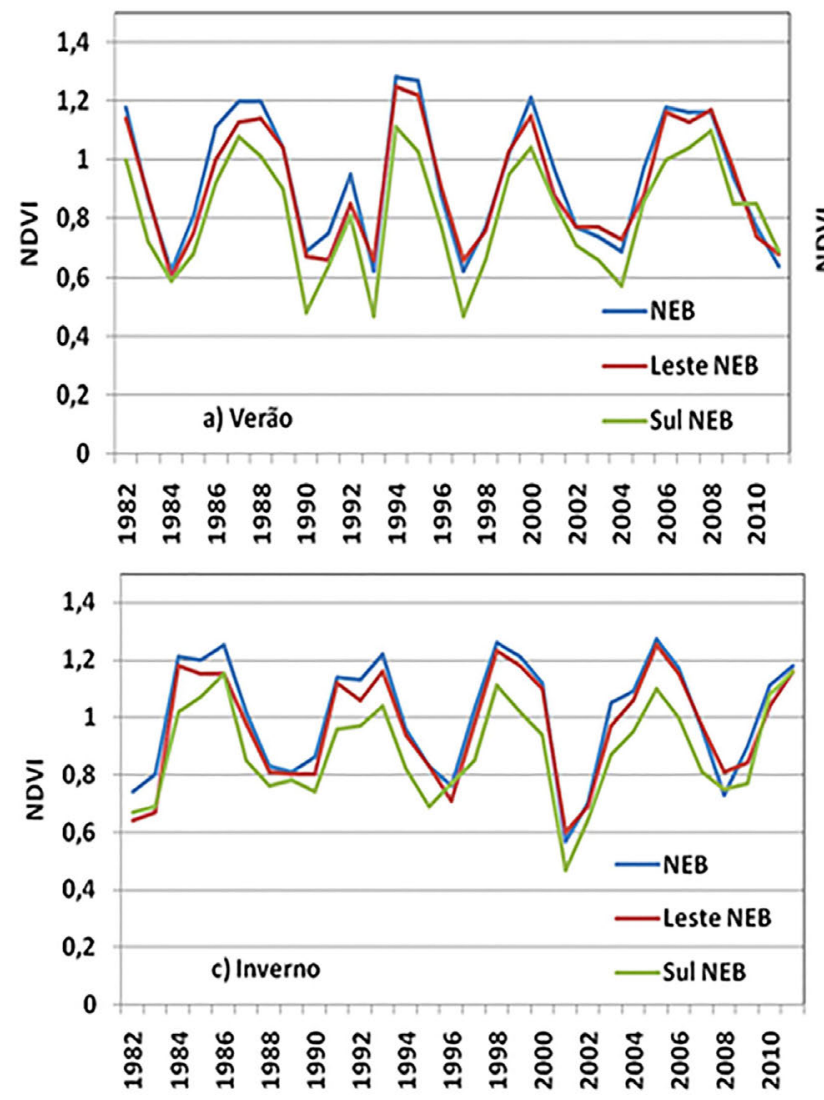

Tabela 3 - Classificação do coeficiente de correlação.

\begin{tabular}{lc}
\hline Faixa & Classificação \\
\hline 1 & Perfeita \\
0,7 a 0,9 & Forte \\
0,4 a 0,7 & Moderada \\
0,2 a 0,4 & Fraca \\
0 & Sem correlação \\
\hline
\end{tabular}

Fonte: Devore (2006).

- Os dados de saída das compilações das rotinas Fortran foram disponibilizados em gráficos gerados pelo software GrADS - Grid Analysis and Display System. O Sistema de Análise e Exibição de Grade é uma ferramenta interativa usada para manipulação e visualização de dados de ciências da terra que usa um ambiente de dados de até 4 dimensões: longitude, latitude, nível vertical e tempo.

\section{Resultados e Discussões}

A Fig. 1 mostra a variabilidade sazonal interanual do NDVI médios (verão-1a, outono-1b, inverno-1c, primavera-1d), paras as sub-regiões: leste do NEB, semiáridas do NEB e sul do NEB.
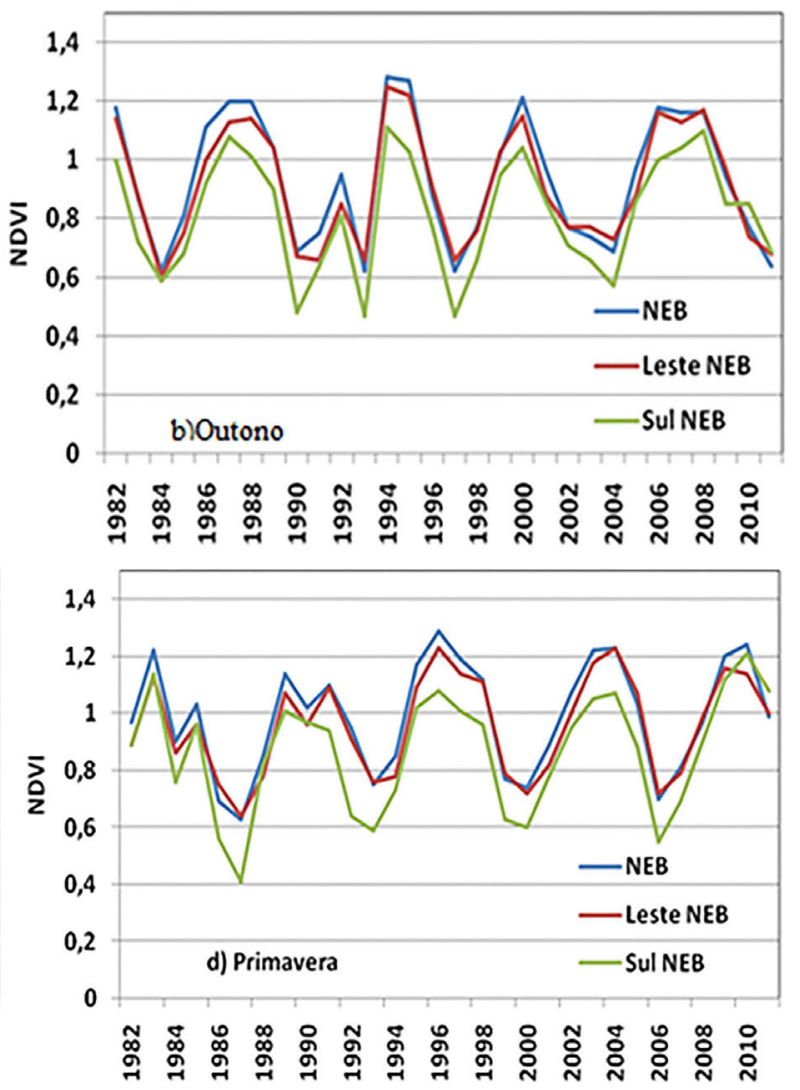

Figura 1 - Variabilidade média sazonal interanual do NDVI (1982-2011) para região semiárida do NEB. a) Verão b) Outono c) Inverno e d) Primavera. 
Nota-se que em todas as figuras há uma variabilidade cíclica (senoidal) com os valores de $N D V I$ oscilando entre 0,4 a 1,2 . Em geral, maiores valores de $N D V I$ indicam uma região com maior atividade fotossintética da vegetação, o que implica em cobertura vegetal mais robusta. Na maioria do casos essa relação NDVIxPrecipitação é linear conforme Lucas e Schuler (2007), apresentando variação para anos com maior ou menor índices de chuva nessas áreas do NEB. Pode-se observar nos gráficos que em alguns anos o $N D V I$ apresentou valores acima de 1,0. Podemos inferir que esses resultados estão associados com anos de La Niña (1985, 1988-1989, 1995 1996, 1998-1999-2000, 2005-2006-2007-2008) contribuindo com chuvas mais regulares no NEB. Enquanto para alguns anos com valores de $N D V I$ menores que 0,5 as chuvas foram mais irregulares compatíveis com os anos de ocorrência de El Niños (1982-1983, 1986-1987, 19911992, 1997-1998).

Uma outra característica observada nessas figuras é que nas estações de inverno e primavera (Fig. 1c e 1d) em todas as regiões as curvas estão fora de fase com as estações de verão e outono (Fig. 1a e 1b), isto é, quando no "verão" e "outono" ocorreram período de anos com o $N D V I$ assumindo valores acima de 1,0, para o "inverno" e "primavera" essas valores decresceram, indicando menos atividade de fotosssintese pela cobertura vegetal, o que é consistente com estações mais secas nessas regiões do NEB. Pois o NDVI é controlado pela umidade, vários fatores causam alterações na leitura da vegetação segundo Gomes et al. (2019), promovendo ruídos que possam resultar em incertezas associadas aos registros de NDVI e sua suscetibilidade e sensibilidade dos efeitos atmosféricos. Santos e Negri (1996) também relataram que o NDVI possui uma relação linear mais evidente com a precipitação, quando avaliamos regiões, cuja precipitação não ultrapassa $50 \mathrm{~mm} / \mathrm{mês}$, como algumas áreas das regiões semiáridas do NEB. Porém quando o total de precipitação mensal é elevado essa relação não é tão perceptível.

As Figs. 2 e 3 mostram a variabilidade espacial para o NEB do percentual de anos nessas três décadas para o $T C I$ e VCI. Para os resultados encontrados na pesquisa deve-se observar que, para valores menores que $\downarrow 30$ indicam condições de estresse, maiores que $\uparrow 30$ e menores que $\downarrow 40$, indicam condições normais sem estresse térmico ou hídrico e com valores maiores que $\uparrow 40$ indicam condições ótimas sem estresse térmico e ou hídrico (Kogan e Sullivan, 1993).

Na Fig. 2 foi analisada a variabilidade de $T C I$, por décadas (1982 a 2011) os resultados foram classificados como "estresse térmico", "condições normais" ou "ótimas condições" ao meio ambiente. Nessa seção buscou-se analisar o estresse vegetativo térmico (TCI - Fig. 2) e por mistura de umidade (VCI - Fig. 3) por décadas. Foi utilizado o percentual de anos por décadas (1982-1991, 1992-2001 e
2002-2011) de condições de estresse vegetativo ou não, em relação aos dados dos índices médios de $T C I$ e $V C I$, levando em consideração algumas décadas nessa série histórica possuírem maiores influência do fenômeno EL Niño e La Niña (Tabela 1).

Podemos inferir pelos resultados observados na Fig. 2 que o percentual encontrado de áreas com estresse em toda a região NEB ficou em torno ou menor que $10 \%$, o percentual de áreas com condição consideradas normais ficou entre $10 \%$ chegando até $30 \%$ (em algumas áreas). Dessa forma o resultado da análise da variabilidade de $T C I$ para a região $\mathrm{NEB}$, considera que a região possui um percentual de $70 \%$ considerado como "ótima condição".

As condições de normalidade, segundo os dados de VCI (Fig. 3) são consideradas como "ótimas" para a vegetação e ao meio ambiente em grande parte do NEB. Os resultados mostraram percentuais em torno ou excedendo os $70 \%$ de área para todas as três décadas de estudo. $\mathrm{O}$ percentual de áreas com estresse (10\%) e condição normal $(30 \%)$ possuem percentuais bem parecidos com os resultados obtidos para o TCI.

O VCI e TCI são relacionados de forma inversamente proporcional com as condições de estresse vegetativo. Valores baixos de VCI representam condições de estresse na vegetação. Já valores baixos de $T C I$ indicam valores altos e extremos de temperatura da superfície e valores altos de TCI correspondem a valores baixos de temperatura segundo Kogan (1997). Os percentuais de $T C I$ e $V C I$ avaliados por décadas nas Figs. 2 e 3 demonstraram valores correlacionados como "ótima" condição.

Foi analisada ainda a variabilidade interanual de $V C I$ e $T C I$ em toda a área do NEB dessa série histórica (1982 a 2011), conforme a classificação como: área de estresse térmico ou de estresse de mistura que resultou em duas Tabelas: 4 para $V C I$ e 5 para $T C I$.

Analisando os percentuais das tabelas pode-se observar que na maior parte dos meses dos anos entre 1982-2011, os maiores percentuais de áreas apresentaram condições entre normais a ótimas para toda a região NEB. Ressalta-se ainda, que foram observados maiores percentuais nos anos de 1983 (VCI), 1995 (TCI) e 2006 (TCI) respectivamente $0,19 \%, 0,26 \%$ e $0,24 \%$ de áreas com condições de estresse térmico e hídrico, esse valores podem ser em virtude de anomalia "El Niño" ter ocorrido nesse período 1983, 1995 e 2006 (conforme a Tabela 1).

Fortaleza, Campos Sales e Jaguaruana, pertencem ao estado do Ceará localizadas no litoral, setor central e sul do Estado e região do Cariri, respectivamente. Pode-se verificar na série historica (1979 a 2015) dos gráficos da Fig. 4 que as mesmas apresentam médias de precipitação interanuais diferentes.

As médias de precipitações anuais desses municípios são: Fortaleza entre $1100 \mathrm{~mm}$ a $1300 \mathrm{~mm}$, Campos Sales entre $701 \mathrm{~mm}$ a $900 \mathrm{~mm}$ e Jaguaruana entre $500 \mathrm{~mm}$ a $700 \mathrm{~mm}$ anuais. Segundo Salati et al. (2007) há uma rela- 
a) TCI - Decada (1982-1981)

b) TCI - Decada (1882-2001)

c) TCI - Decada (2002-2011)

Percentual de Anos Estresse Termico Percentual de Anos Estresse Termico Percentual de Anos Estresse Termico
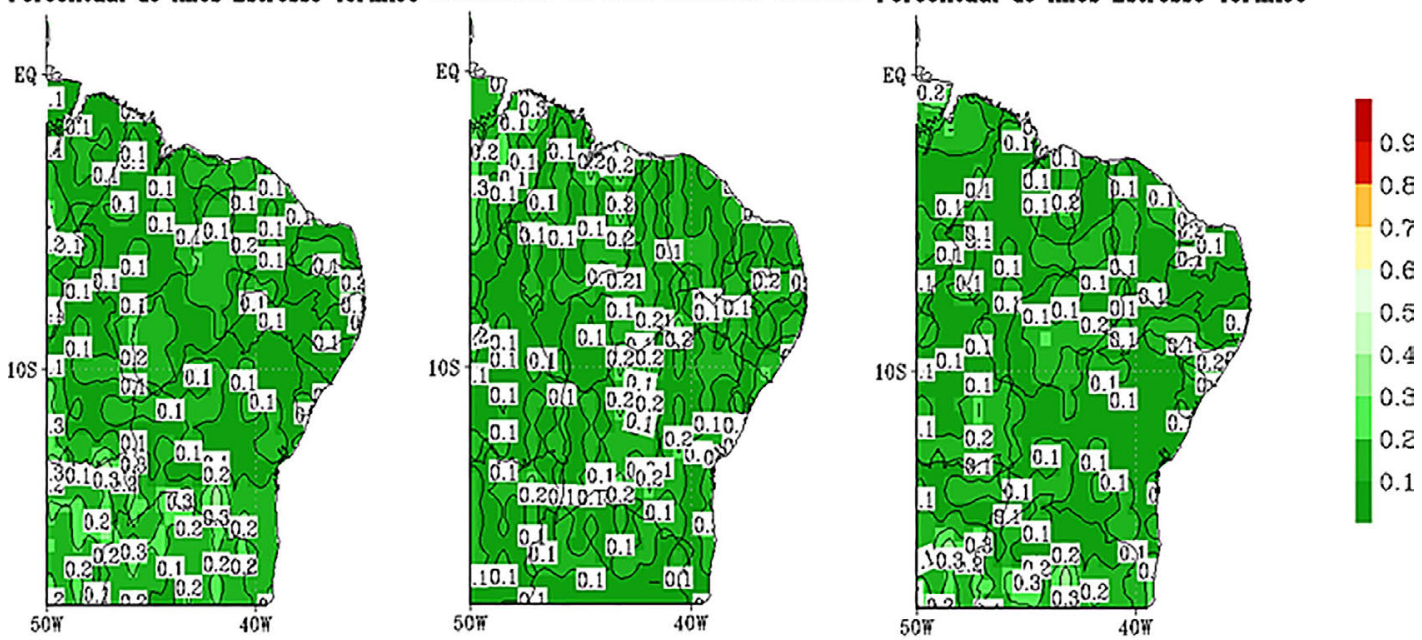

d) TCI - Decada (1882-1981)

e) TCl - Decada (1982-2001)

f) TCI - Decada (2002-2011)

Percentual de Anos Condicao Normal Percentual de Anos Condicao Normal Percentual de Anos Condicao Normal
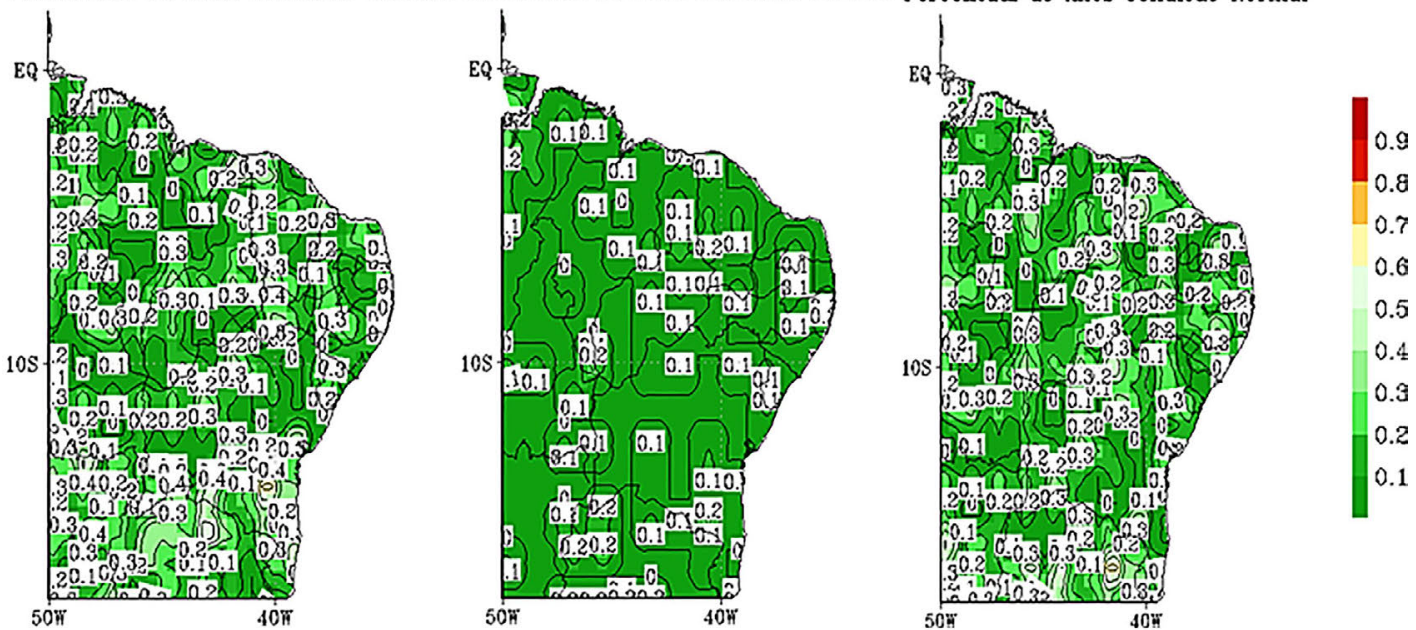

g) TCI - Decada (1982-1891)

h) TCI - Decada (1992-2001)

i) TCI - Decada (2002-2011)

Percentual de Anos Condicao Otima Percentual de Anos Condicao Otima Percentual de Anos Condicao Otima
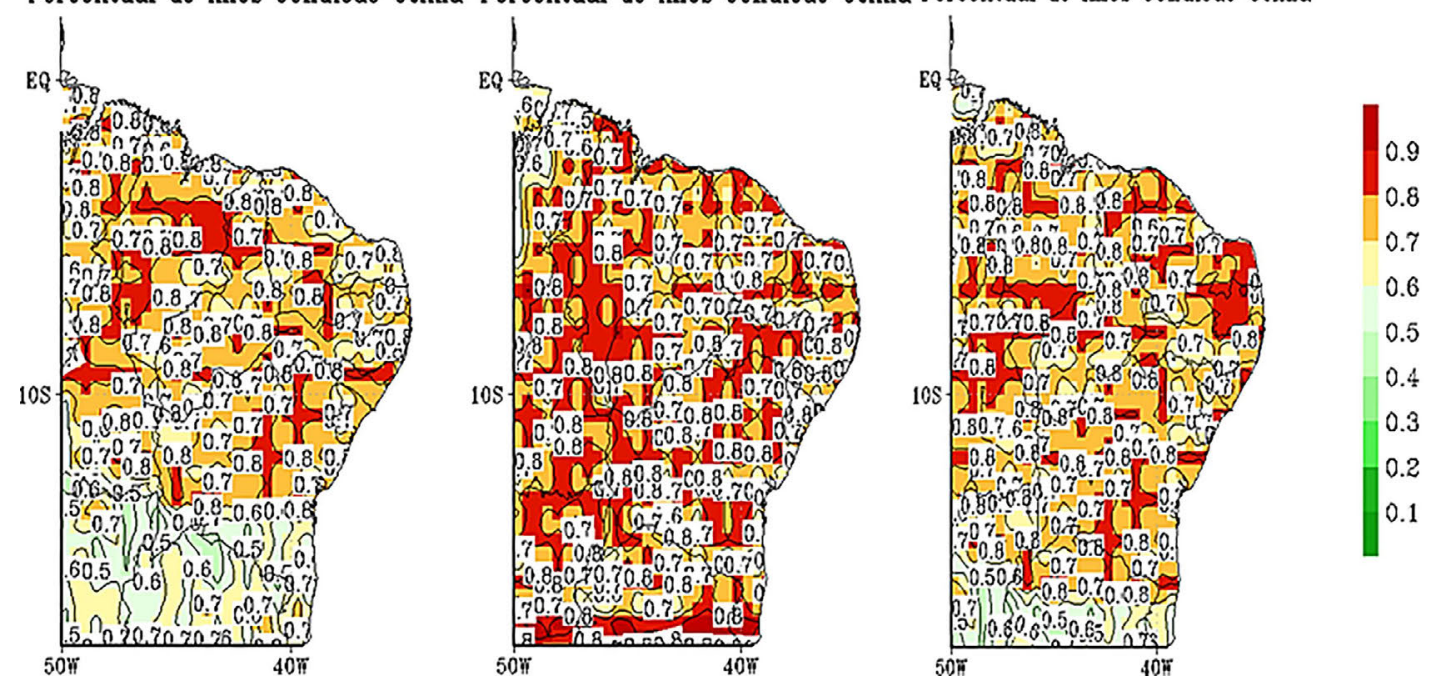

Figura 2 - Variabilidade do percentual de anos (por décadas) de TCI classificado como estresse térmico, condições normais ou ótimas ao meio ambiente. a) estresse (1982-1991), b) estresse (1992-2001), c) estresse (2001-2011), d) normal (1982-1991), e) normal (1992-2001), f) normal (2002-2011), g) ótima (1982-1991), h) ótima (1992-2001) e i) ótima (2002-2011). 


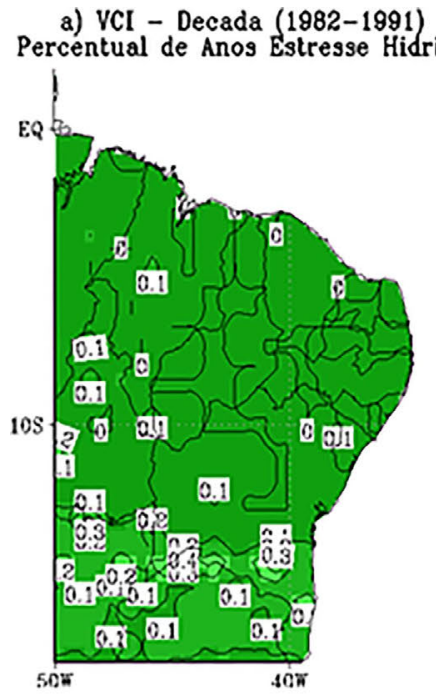

b) $\mathrm{VCl}$ - Decada (1982-2001)

c) $\mathrm{VCI}$ - Decada (2002-2011)

Percentual de Anos Estresse Hidrico Percentual de Anos Estresse Hidrico Percentual de Anos Estresse Hidrico
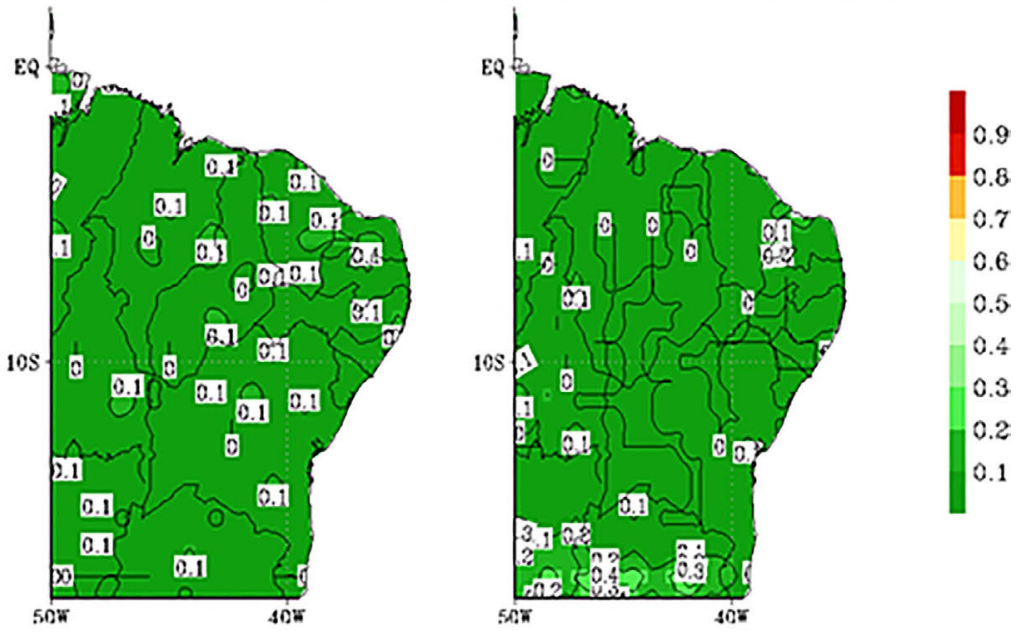

d) VCl - Decada (1982-1891)

e) YCI - Decada (1892-2001)

t) $\mathrm{VCl}$ - Decada (2002-2011)

Percentual de Anos Condicao Normal Percentual de Anos Condicao Normal Percentual de Anos Condicao Normal
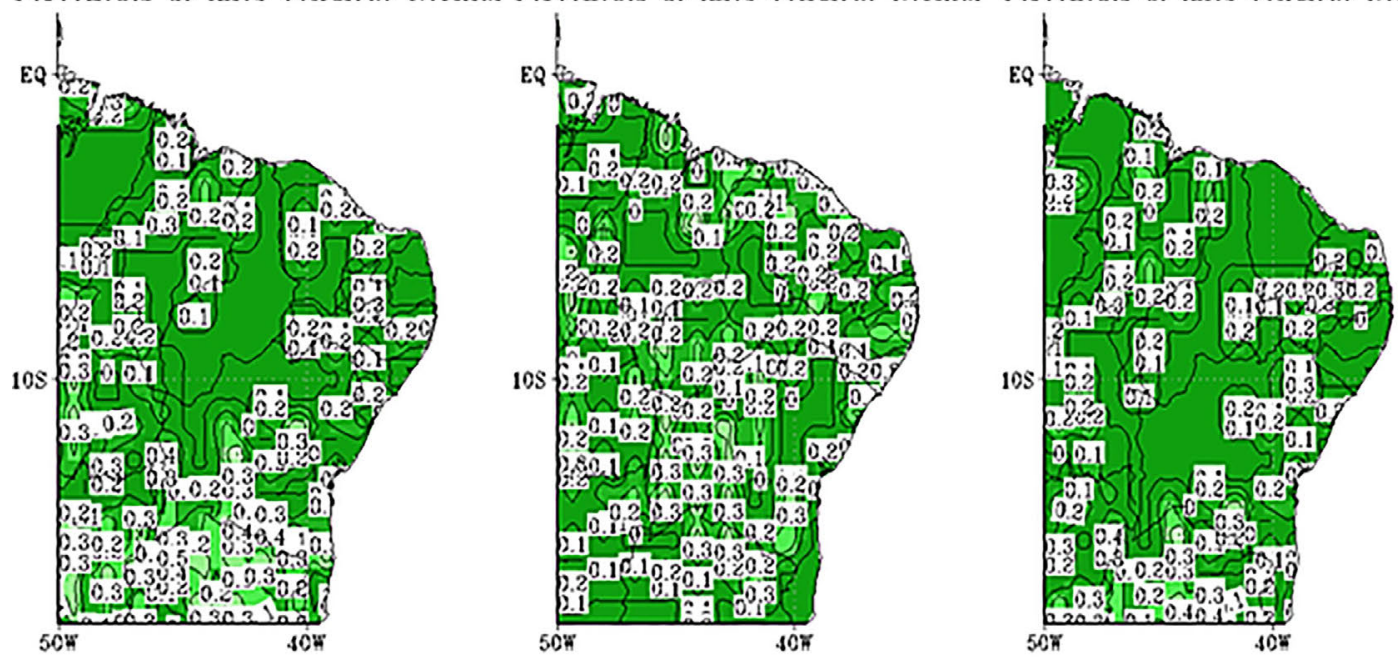

g) VCI - Decada (1882-1991)

h) VCI - Decada (1892-2001)

i) VCI - Decada (2002-2011)
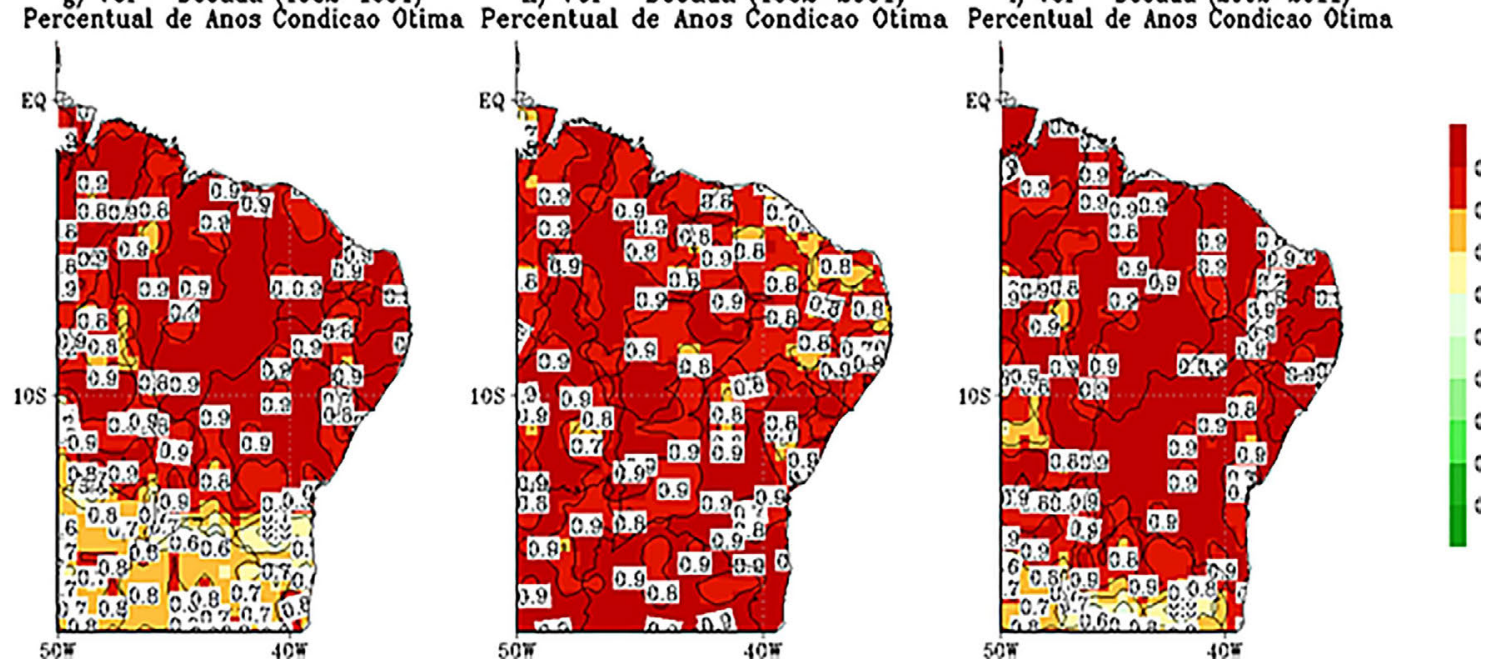

Figura 3 - Variabilidade do percentual de anos por décadas do $V C I$ e sua classificação como estresse térmico, condições normais ou ótimas ao meio ambiente. a) estresse (1982-1991), b) estresse (1992-2001), c) estresse (2001-2011), d) normal (1982-1991), e) normal (1992-2001), d) normal (20022011), f) ótima (1982-1991), g) ótima (1992-2001) e g) ótima (2002-2011). 
ção forte entre a temperatura média e a precipitação em uma determinada região. Nessa seção foi analisada a relação linear mensal entre a temperatura do ar nas três cidades do Ceará, e os índices de $T C I$ e $V C I$ médios nas coordenadas geográficas, localização de cada município, utilizando o coeficiente de correlação de Peaeson. Os me-
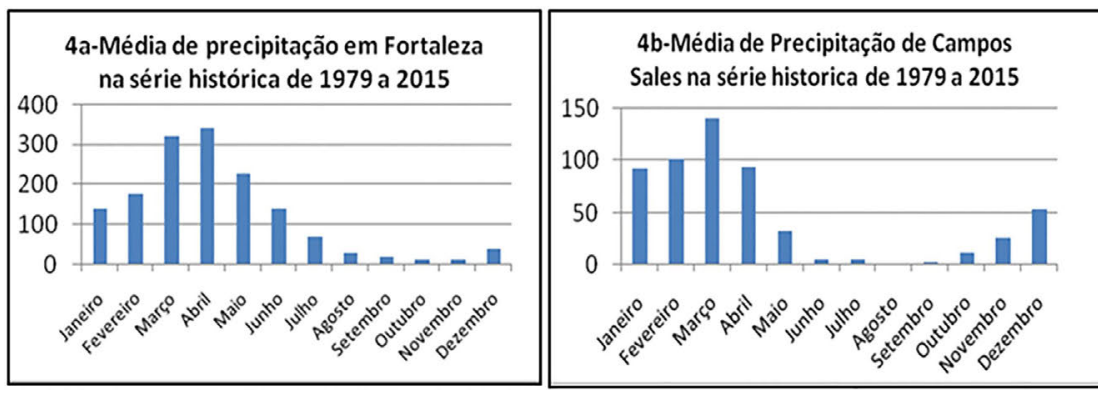

4c-Média de precipitação em Jaguaruana na série histórica de 1979 a 2015

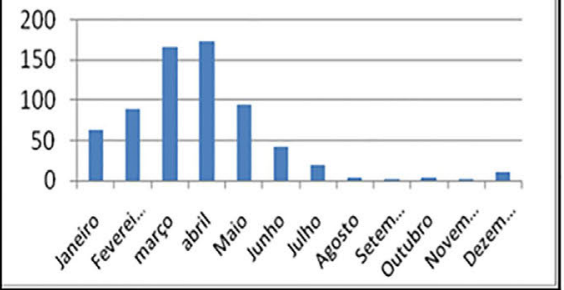

Figura 4 - Média da precipitação dos municípios de Fortaleza (4a), Campos Sales (4b) e Jaguaruana (4c) na série histórica de 1979 a 2015.

Tabela 4 - Variabilidade interanual das áreas com condições de $V C I$ associadas a estresse, normalidade e condições ótimas. Média na área semiárida do NEB $\left(45^{\circ} \mathrm{W}-37^{\circ} \mathrm{W}\right.$ e $\left.12^{\circ} \mathrm{S}-2^{\circ} \mathrm{S}\right)$.

\begin{tabular}{|c|c|c|c|c|c|c|c|}
\hline Ano & $\begin{array}{c}\text { Estresse } \\
\text { Área }\left(\mathrm{km}^{2}\right)\end{array}$ & $\begin{array}{c}\text { Estresse } \\
(\%)\end{array}$ & $\begin{array}{c}\text { Normal } \\
\text { Área }\left(\mathrm{km}^{2}\right)\end{array}$ & $\begin{array}{c}\text { Normal } \\
\%\end{array}$ & $\begin{array}{c}\text { Ótima } \\
\text { Área }\left(\mathrm{km}^{2}\right)\end{array}$ & $\begin{array}{c}\text { Ótima } \\
\%\end{array}$ & Área $\left(\mathrm{km}^{2}\right)$ \\
\hline 1982 & 340761,59 & 0,05 & 545218,56 & 0,08 & 6805690,50 & 99,86 & 6815232,00 \\
\hline 1983 & 1294894,13 & 0,19 & 340761,59 & 0,05 & 6798875,50 & 99,76 & 6815232,00 \\
\hline 1984 & 0,00 & 0,00 & 0,00 & 0,00 & 6815232,00 & 100,00 & 6815232,00 \\
\hline 1985 & 68152,32 & 0,01 & 408913,91 & 0,06 & 6810461,50 & 99,93 & 6815232,00 \\
\hline 1986 & 0,00 & 0,00 & 136304,64 & 0,02 & 6813869,00 & 99,98 & 6815232,00 \\
\hline 1987 & 136304,64 & 0,02 & 613370,88 & 0,09 & 6807735,00 & 99,89 & 6815232,00 \\
\hline 1988 & 136304,64 & 0,02 & 272609,28 & 0,04 & 6811143,00 & 99,94 & 6815232,00 \\
\hline 1989 & 204456,95 & 0,03 & 204456,95 & 0,03 & 6811143,00 & 99,94 & 6815232,00 \\
\hline 1990 & 340761,59 & 0,05 & 340761,59 & 0,05 & 6808417,00 & 99,90 & 6815232,00 \\
\hline 1991 & 204456,95 & 0,03 & 408913,91 & 0,06 & 6809098,50 & 99,91 & 6815232,00 \\
\hline 1992 & 0,00 & 0,00 & 0,00 & 0,00 & 6815232,00 & 100,00 & 6815232,00 \\
\hline 1993 & 0,00 & 0,00 & 0,00 & 0,00 & 6815232,00 & 100,00 & 6815232,00 \\
\hline 1994 & 68152,32 & 0,01 & 204456,95 & 0,03 & 6813187,50 & 99,97 & 6815232,00 \\
\hline 1995 & 0,00 & 0,00 & 0,00 & 0,00 & 6814550,50 & 99,99 & 6815232,00 \\
\hline 1996 & 0,00 & 0,00 & 68152,32 & 0,01 & 6814550,50 & 99,99 & 6815232,00 \\
\hline 1997 & 68152,32 & 0,01 & 272609,28 & 0,04 & 6811824,00 & 99,95 & 6815232,00 \\
\hline 1998 & 136304,64 & 0,02 & 204456,95 & 0,03 & 6811824,00 & 99,95 & 6815232,00 \\
\hline 1999 & 68152,32 & 0,01 & 136304,64 & 0,02 & 6813187,50 & 99,97 & 6815232,00 \\
\hline 2000 & 68152,32 & 0,01 & 136304,64 & 0,02 & 6813187,50 & 99,97 & 6815232,00 \\
\hline 2001 & 0,00 & 0,00 & 0,00 & 0,00 & 6815232,00 & 100,00 & 6815232,00 \\
\hline 2002 & 68152,32 & 0,01 & 136304,64 & 0,02 & 6813187,50 & 99,97 & 6815232,00 \\
\hline 2003 & 0,00 & 0,00 & 68152,32 & 0,01 & 6813869,00 & 99,98 & 6815232,00 \\
\hline 2004 & 204456,95 & 0,03 & 272609,28 & 0,04 & 6810461,50 & 99,93 & 6815232,00 \\
\hline 2005 & 204456,95 & 0,03 & 204456,95 & 0,03 & 6811143,00 & 99,94 & 6815232,00 \\
\hline 2006 & 0,00 & 0,00 & 0,00 & 0,00 & 6815232,00 & 100,00 & 6815232,00 \\
\hline 2007 & 0,00 & 0,00 & 68152,32 & 0,01 & 6814550,50 & 99,99 & 6815232,00 \\
\hline 2008 & 68152,32 & 0,01 & 340761,59 & 0,05 & 6811143,00 & 99,94 & 6815232,00 \\
\hline 2009 & 0,00 & 0,00 & 136304,64 & 0,02 & 6813869,00 & 99,98 & 6815232,00 \\
\hline 2010 & 68152,32 & 0,01 & 136304,64 & 0,02 & 6813187,50 & 99,97 & 6815232,00 \\
\hline 2011 & 136304,64 & 0,02 & 204456,95 & 0,03 & 6811824,00 & 99,95 & 6815232,00 \\
\hline
\end{tabular}


Tabela 5 - Variabilidade interanual das áreas com condições de $T C I$ associadas a estresse, normalidade e condições ótimas. Média na área semiárida do $\operatorname{NEB}\left(45^{\circ} \mathrm{W}-37^{\circ} \mathrm{W}\right.$ e $\left.12^{\circ} \mathrm{S}-2^{\circ} \mathrm{S}\right)$.

\begin{tabular}{|c|c|c|c|c|c|c|c|}
\hline Ano & $\begin{array}{c}\text { Estresse } \\
\text { Área }\left(\mathrm{km}^{2}\right)\end{array}$ & $\begin{array}{c}\text { Estresse } \\
(\%)\end{array}$ & $\begin{array}{c}\text { Normal } \\
\text { Área }\left(\mathrm{km}^{2}\right)\end{array}$ & $\begin{array}{c}\text { Normal } \\
\%\end{array}$ & $\begin{array}{c}\text { Ótima } \\
\text { Área }\left(\mathrm{km}^{2}\right)\end{array}$ & $\begin{array}{c}\text { Ótima } \\
\%\end{array}$ & Área $\left(\mathrm{km}^{2}\right)$ \\
\hline 1982 & 136304,64 & 0,02 & 408913,91 & 0,06 & 6809098,50 & 99,91 & 6815232,00 \\
\hline 1983 & 136304,64 & 0,02 & 68152,32 & 0,01 & 6813869,00 & 99,98 & 6815232,00 \\
\hline 1984 & 0,00 & 0,00 & 0,00 & 0,00 & 6815232,00 & 100,00 & 6815232,00 \\
\hline 1985 & 204456,95 & 0,03 & 340761,59 & 0,05 & 6809779,50 & 99,92 & 6815232,00 \\
\hline 1986 & 1363046,38 & 0,20 & 613370,88 & 0,09 & 6796149,50 & 99,72 & 6815232,00 \\
\hline 1987 & 204456,95 & 0,03 & 681523,19 & 0,10 & 6806372,50 & 99,87 & 6815232,00 \\
\hline 1988 & 204456,95 & 0,03 & 477066,25 & 0,07 & 6808417,00 & 99,90 & 6815232,00 \\
\hline 1989 & 749675,50 & 0,11 & 613370,88 & 0,09 & 6801601,50 & 99,80 & 6815232,00 \\
\hline 1990 & 817827,81 & 0,12 & 1022284,81 & 0,15 & 6796831,00 & 99,73 & 6815232,00 \\
\hline 1991 & 545218,56 & 0,08 & 817827,81 & 0,12 & 6801601,50 & 99,80 & 6815232,00 \\
\hline 1992 & 0,00 & 0,00 & 0,00 & 0,00 & 6815232,00 & 100,00 & 6815232,00 \\
\hline 1993 & 0,00 & 0,00 & 0,00 & 0,00 & 6815232,00 & 100,00 & 6815232,00 \\
\hline 1994 & 204456,95 & 0,03 & 613370,88 & 0,09 & 6807053,50 & 99,88 & 6815232,00 \\
\hline 1995 & 1771960,25 & 0,26 & 340761,59 & 0,05 & 6794786,00 & 99,70 & 6815232,00 \\
\hline 1996 & 408913,91 & 0,06 & 681523,19 & 0,10 & 6804327,00 & 99,84 & 6815232,00 \\
\hline 1997 & 272609,28 & 0,04 & 340761,59 & 0,05 & 6809098,50 & 99,91 & 6815232,00 \\
\hline 1998 & 340761,59 & 0,05 & 204456,95 & 0,03 & 6809779,50 & 99,92 & 6815232,00 \\
\hline 1999 & 885980,13 & 0,13 & 954132,50 & 0,14 & 6796831,00 & 99,73 & 6815232,00 \\
\hline 2000 & 408913,91 & 0,06 & 749675,50 & 0,11 & 6803646,00 & 99,83 & 6815232,00 \\
\hline 2001 & 0,00 & 0,00 & 0,00 & 0,00 & 6815232,00 & 100,00 & 6815232,00 \\
\hline 2002 & 545218,56 & 0,08 & 749675,50 & 0,11 & 6802964,50 & 99,82 & 6815232,00 \\
\hline 2003 & 817827,81 & 0,12 & 954132,50 & 0,14 & 6797512,50 & 99,74 & 6815232,00 \\
\hline 2004 & 613370,88 & 0,09 & 817827,81 & 0,12 & 6800920,00 & 99,79 & 6815232,00 \\
\hline 2005 & 1022284,81 & 0,15 & 613370,88 & 0,09 & 6798875,50 & 99,76 & 6815232,00 \\
\hline 2006 & 1567503,38 & 0,23 & 408913,91 & 0,06 & 6795468,00 & 99,71 & 6815232,00 \\
\hline 2007 & 1022284,81 & 0,15 & 681523,19 & 0,10 & 6798194,00 & 99,75 & 6815232,00 \\
\hline 2008 & 1158589,50 & 0,17 & 545218,56 & 0,08 & 6798194,00 & 99,75 & 6815232,00 \\
\hline 2009 & 613370,88 & 0,09 & 954132,50 & 0,14 & 6799556,50 & 99,77 & 6815232,00 \\
\hline 2010 & 1363046,38 & 0,20 & 545218,56 & 0,08 & 6796831,00 & 99,73 & 6815232,00 \\
\hline 2011 & 1635655,63 & 0,24 & 272609,28 & 0,04 & 6795468,00 & 99,71 & 6815232,00 \\
\hline
\end{tabular}

ses utilizados nesse estudo foram de janeiro a dezembro na série histórica de 1982 a 2011.

$\mathrm{Na}$ Tabela 6 foi apresentada a relação linear entre os índices $T C I$ e $V C I$ e a temperatura do ar na superfície dos municípios de Fortaleza, Campos Sales e Jaguaruana.

Como podemos confirmar a Tabela 6 mostra a correlação estatística de Pearson, entre a temperatura do Ar na superfície, medida nas estações dos municípios e os índices $V C I$ e $T C I$ médios em torno das coordenadas geográficas desses municípios. Pode-se observar que os valores de correlação tiveram pequenas diferenças: Fortaleza entre 0,78 e 0,79; Campos Sales entre 0,85 e 0,81 e Jaguaruana entre 0,83 e 0,81 . Todos os resultados se aproximaram a 0,80. Indicando conforme Devore (2006), uma "Forte"
Tabela 6 - Coeficiente de correlação de Pearson mensal (1982-2011) entre a Temperatura do Ar medida nas estações dos municípios de Fortaleza, Campos Sales e Jaguaruana no Ceará e os índices VCI e TCI médios em torno das coordenadas geográficas desses municípios.

\begin{tabular}{lccc}
\hline & \multicolumn{3}{c}{ Fortaleza } \\
Temperatura & 0,79 & & $T C I$ \\
& & Campos Sales & 0,78 \\
Temperatura & $V C I$ & & $T C I$ \\
& 0,85 & & 0,81 \\
& & Jaguaruana & \\
Temperatura & $V C I$ & & $T C I$ \\
\hline
\end{tabular}


correlação entre a Temperatura do Ar da superfície dos municípios avaliados e os índices obtidos de TCI e VCI.

A análise do teste t-Student avaliou os índices e as temperaturas médias mensais em todos os municípios. $\mathrm{O}$ resultado obteve uma significância estatística de 95\%. Esses valores de correlação inferem que esses dois índices TCI e VCI podem ser indicativos de condições térmicas nessas regiões do Ceará.

\section{Conclusões}

Os resultados de NDVI sazonal e interanual investigados neste estudo apresentaram variações para anos com maiores ou menores índices de chuva nas sub-regiões do NEB devidos as estações de chuva na região. Os valores de NDVI obtidos nestas sub-regiões demonstraram ainda grande influência para anos de contrastes climáticos (El Niño e La Niña) devido a forte relação do $N D V I$ com a precipitação. A análise da relação entre os índices $T C I$ e $V C I$ e a temperatura do ar para a superfície nas três cidades do Ceará (Fortaleza, Jaguaruana e Campos Sales), demonstrou uma correlação forte e com grande significância estatística comprovando que o $T C I$ e $V C I$ são indicativos de condições térmicas nas regiões estudadas e que comprovadamente podem ser usados como "relógio da seca" segundo Kogan (1997), pois seus valores são mais expressivos para regiões com baixos índices de precipitação. As análises do estresse vegetativo térmico (TCI) e por mistura de umidade ( $V C I$ ) por décadas (1982-1991, 1992-2001 e 2002-2001) em toda a região nordeste, resultou em valores bem parecidos, mas condizentes com percentuais considerados como "ótima condição". Podemos inferir que esses resultados obtidos neste estudo indicam que o $V C I, T C I$ e NDVI podem ser utilizados para monitorar o estresse térmico sazonal e interanual na região Nordeste.

\section{Referências}

ALVES, J.M.B.; SOUZA, E.B.; MELLO, N.G.S.; FERREIRA, A.G.; SILVA, R.A.; SAKAMOTO, M.S.; MUNCUNILL, D.F. Avaliação da pré-estação chuvosa: parte I distribuição das chuvas no estado do Ceará. X Congresso Brasileiro de Meteorologia e III Congresso da FLISMET, Brasília, 1998, disponível em http://mtc-m16b.sid.inpe.br/col/cptec.inpe. br/walmeida/2004/10.15.15.23/doc/Alves_Avaliacao\% $20 \mathrm{da} \% 20$ pre-estacao\%20chuvosa.pdf, acesso em 22 jan.2020.

ANDREOLI, R.V.; KAYANO, M.T. A importância relativa do atlântico tropical sul e pacífico leste na variabilidade de precipitação do nordeste do Brasil. Revista Brasileira de Meteorologia, v. 22, n. 1, p. 63-74, 2007.

CAVALCANTI, I.F.A. Um Estudo Sobre as Interações Entre os Sistemas de Circulação de Escala Sinótica e Circulações Locais. Dissertação de Mestrado, Instituto de Pesquisas Especiais - INPE 2494 TDL/097, p. 54-107, 1982.
CHIANG, J.C.H.; KUSHNIR, Y.; ZEBIAK, S.E. Interdecenal changes in castern Pacific ITCZ variability and its influence on the Atlantic ITCZ. Geophysical Research Letters, v. 27, n. 22, p. 3687-3690, 2000.

DEVORE, J.L. Probabilidade e Estatística: Para Engenharia e Ciências. Tradução: Joaquim Pinheiro Nunes da Silva, 6 ed., São Paulo: Edit. Pioneira Thomson Learning, p. 682, 2006.

ECHER, M.P.S.; MARTINS, F.R.; PEREIRA, E.B. A importância dos dados de cobertura de nuvens e de sua variabilidade: Metodologias para aquisição de dados. Revista Brasileira de Ensino de Física, v. 28, n. 3, p. 341-352, 2006.

GAN, M.A. Um Estudo Observacional Sobre as Baixas da Alta Troposfera nas Latitudes Subtropicais do Atlântico Sul e Leste do Brasil. Dissertação de Mestrado em Pesquisas Espaciais, Programa de em Meteorologia, Instituto Nacional de Pesquisas Espaciais - INPE, São José dos Campos, 82 p. 1982, disponível em: http://mtc-m16b.sid. inpe.br/col/sid.inpe.br/jeferson/2005/06.21.17.31/doc/publi cacao.pdf, acesso em 24 Abr. 2017.

GOMES, A.R.S.; ALVES, J.M.B.; SILVA, E.M.S.; GOMES, M.R.S.; GOMES, C.R.S. Estudo da relação entre a variabilidade dos índices de vegetação e temperatura da região Nordeste do Brasil. Revista Brasileira de Meteorologia, v. 34, n. 3, p. 359-368. 2019.

HASTENRATH, S.; HELLER, L. Dynamics of climatic hazards in Northeast Brazil. Quarterly Journal of the Royal Meteorological Society, v. 103, n. 435, p. 77-92, 1977.

HUANG, G.; PAES, A.T. Posso usar o teste t de Student quando preciso comparar três ou mais grupos? Einstein: Educ. Contin. Em Saúde, v. 7, n. 2, p. 63-64, 2009.

KOGAN, J.; SULLIVAN, J. Development of global droughtwatch system using NOAA/AVHRR data NOAA/NESDIS/ ORA/Satellite Research Laboratory. Advances in Space Research, v. 13, n. 5, p. 219-222, 1993.

KOGAN, F.N. Application of vegetation index and brightness temperature for drought detection. Advances in Space Research, v. 15, p. 91-100, 1995.

KOGAN, J. Global drought watch from space. Bulletin of American Meteorology Society, v. 78, n. 4, p. 621-636. 1997.

KOUSKY, V.E. Frontal influences on the Northeast Brazil. Monthly Weather Review, v. 107, n. 9, p. 1140-1153, 1979.

KOUSKY, V.E.; CHU, P.S. Flutuations in annual rainfall for northeast Brazil. Journal Meteorological Society, v. 56, n. 5, p. 457-465, 1978.

LUCAS, A.A.; SCHULER, C.A.B. Análise do NDVI/NOAA em cana-de-açúcar e Mata Atlântica no litoral norte de Pernambuco, Brasil. Revista Brasileira de Engenharia Agrícola e Ambiental, v. 11, n. 6, p. 607-614, 2007.

MENEZES, H.E.A.; BRITO, J.I.B.; SANTOS, C.A.C.; SILVA, L.L. A relação entre a temperatura da superfície dos oceanos tropicais e a duração dos veranicos no Estado da Paraíba. Revista Brasileira de Meteorologia, v. 23, n. 2, p. 152-161, 2008.

PEREZ, L.P.; FERREIRA, N.J.; SHIMABUKURO, Y.E.; ADAMI, M. Análise de NDVI no nordeste brasileiro por componentes principais: resultados preliminares. Anais XI SBSR, Belo Horizonte, 2003. INPE, p. 2869, 2003, dis- 
ponível em http://marte.sid.inpe.br/rep/ltid.inpe.br/sbsr/ 2002/11.18.19.42?mirror=dpi.inpe.br/banon/2003/ 12.10.19.30.54\&metadatarepository=ltid.inpe.br/sbsr/ 2002/11.18.19.42.45, acesso em 18 Mai. 2017.

RAO, V.B.; LIMA, M.C.D.; FRANCHITO, S.H. Seasonal and interannual variations of rainfall over eastern Northeast Brazil. Journal of Climate, v. 6, n. 9, p. 1754-1763, 1993.

ROCHA, G.F.; FERREIRA JÚNIOR, L.G.; FERREIRA, N.C.; FERREIRA, M.E.; SILVA, G.N.F. Detecção de desmatamentos no bioma Cerrado entre 2002 e 2009: Padrões, tendências e impactos, Revista Brasileira de Cartografia, v. 63, p. 341-349, n. 3, 2010.

SALATI, E.; CAMPANHOL, T.; VILLA NOVA, N. Caracterização do clima atual e definição das alterações climáticas para o território brasileiro ao longo do Século XXI. In: Relatório 4 Tendências de Variações Climáticas para o Brasil no Século XX e Balanços Hídricos para Cenários Climáticos para o Século XXI, 182 p. 2007, disponivel em http://mudancasclimaticas.cptec.inpe.br/ rmclima/pdfs/ prod_probio/Relatorio_4.pdf, acesso em 22 jun.2020. Rio de Janeiro.

SANTOS, C.A.C. Estimativas e Tendências de Índices de Deteção de Mudanças Climáticas com base na precipitação diária no Rio Grande do Norte e na Paraíba. Dissertação de Mestrado, Programa de Pós-Graduação em Meteorologia, Universidade Federal de Campina Grande. Campina Grande, 98 p, 2006, disponÍvel em http://www. dca.ufcg.edu.br/posgrad_met/dissertacoes/CarlosAntonioC Santos_2006.pdf, acesso em 22 jun 2020.

SANTOS, C.A.C. dos; BRITO, J.I.B. de; RAO, T.V.R.; MENEZES, H.E.A. Tendências dos índices de precipitação no Estado do Ceará. Revista Brasileira de Meteorologia, v. 24, n. 1, p. 39-47, 2009.

SANTOS, P.; NEGRI. A.J. Comparison of the normalized difference vegetation index and rainfall for the Amazon and Northeastern Brazil, Journal Applied of Meteorology, v. 36, n. 7, p. 958-965, 1996.

SERVAIN, J.; LUKAS, S. Climatic Atlas of the Tropical Atlantic Wind Stress and Sea Surface Temperature 1985-1989. Plouzené: Service de La Documentation et dês Publications (S.D.P.), 133 p, disponível em: https://core.ac. uk/download/pdf/39865007.pdf, acesso em 17 Jan. de 2018.

SILVA, B.B.; LOPES, G.M.; AZEVEDO, P.V. Determinação do albedo de áreas irrigadas com base em imagens LANDSAT 5-TM. Revista Brasileira de Agrometereologia, v. 13, n. 2, p. 11-21, 2006.

UVO, C.R.B.; BERNDTSSON, R. Regionalization and Spatial Properties of Ceará State Rainfall in Northeast Brazil, Journal of Geophysical Research, v. 101, n. D2, p. 42214233, 1996.
WITTE, R.S.; WITTE, J.S. Estatística. Rio de Janeiro: LTC, p. $486,2005$.

\section{Endereços de Internet}

FUNDAÇÃO CEARENSE DE METEOROLOGIA E RECURSOS HÍDRICOS - FUNCEME, disponível em http://www. funceme.br/, acesso em 09 de maio de 2016.

GrADS - Grid Analysis and Display System, disponível em http://opengrads.org/, acesso em 10 Mai. 2016.

INSTITUTO BRASILEIRO DE GEOGRAFIA E ESTATÍSTICA, IBGE. Geografia do Brasil. Região Nordeste. Rio de Janeiro. Atlas Nacional do Brasil. 1985, disponível em https://biblioteca.ibge.gov.br/index.php/biblioteca-cata logo? $\mathrm{id}=287917 \&$ view $=$ detalhes, acesso em 12 jun. de 2020.

INSTITUTO NACIONAL DE METEOROLOGIA, INMET, disponível em :http://www.inmet.gov.br/portal/index.php? $\mathrm{r}=$ home/page \&page=omm, acesso em 09 maio 2017.

INSTITUTO NACIONAL DE PESQUISAS ESPACIAIS, INPE 2005, disponível em :http://www.inpe.br/, acesso em 09 mai. 2017.

INTERGOVERNMENTAL PANEL ON CLIMATE CHANGE IPCC, 2007. Summary for Policymakers, in Climate Change 2007: Impacts, Adaptation and Vulnerability. Contribution of Working Group II to the Fourth Assessment Report of the Intergovernmental Panel on Climate Change, disponivel em http://www.ipcc.ch/publications_and_data/ publications_ipcc_fourth_assessment_report_synthesis_re port.html, acesso em 09 de mar. 2018.

NATIONAL DISASTER MANAGEMENT CENTRE, - NDMC, Inaugural Annual Report 2006-2007. National Disaster Management Centre, Provincial and Local Government Department, Pretoria, South Africa, 172 páginas, 2007, disponivel em http://citeseerx.ist.psu.edu/viewdoc/download? doi=10.1.1.423.3231\&rep=rep1\&type=pdf, acesso em 28 Jun de 2019.

NATIONAL OCEANIC AND ATMOSPHERIC ADMINISTRATION - NOAA/NESDIS Disponível em https://www. nesdis.noaa.gov/, acesso em 28 Jun. 2017.

PAINEL BRASILEIRO DE MUDANÇAS CLIMÁTICAS PBMC, Contribuição do Grupo de Trabalho 2 ao Primeiro Relatório de Avaliação Nacional do Painel Brasileiro de Mudanças Climáticas. Sumário Executivo do GT2, Rio de Janeiro, Brasil. 28 p., 2013, disponível em http://www. pbmc.co ppe.ufrj.br/documentos/GT2_sumario_portu gues_v2.pdf, acesso em 12 de Jun de 2020.

License information: This is an open-access article distributed under the terms of the Creative Commons Attribution License (type CC-BY), which permits unrestricted use, distribution and reproduction in any medium, provided the original article is properly cited. 